\title{
MODERNIDADE PERIFÉRICA E DESCOLONIZAÇÃO EPISTÊMICA A contribuição do marxismo paulista
}

\section{José Henrique Bortoluci}

\section{Introdução}

A constituição da modernidade no Brasil é um capítulo dos mais relevantes para uma discussão sobre o uso de raciocínios e categorias eurocêntricas, quando o que se tem em tela é uma sociedade "não tipicamente" ocidental ou central. Paulo Emílio Salles Gomes aponta o problema de que "não somos europeus nem americanos do norte, mas destituídos de cultura original, nada nos é estrangeiro, pois tudo o é. A penosa construção de nós mesmos se desenvolve na dialética rarefeita entre o não ser e o ser outro" (apud Arantes, 1992, p. 15). Esse "entrelaçamento dual entre o mesmo e o outro" (Arantes, 1992, p. 16) é também captado ainda pelo crítico literário Antonio Candido: "o brasileiro não pode deixar de viver pendurado no Ocidente e ele deve tentar

Artigo recebido em 22/11/2011

Aprovado em 02/05/2013 não viver pendurado no Ocidente. Ele deve tentar fazer uma cultura dele, mas a cultura que ele pode fazer é uma cultura pendurada no Ocidente [...]. Nós somos o outro e o outro é necessário para a identidade do mesmo" (apud Arantes, 1992, p. 16). Esse drama da autoidentidade, tão explorado pelo ensaísmo e pela crítica cultural nacionais, aponta uma contradição plena de consequências no seio da experiência cultural e social brasileira.

Esse dilema difícil de equacionar marca a experiência intelectual brasileira desde seu início, em suas manifestações artísticas, sociais e econômicas. Não é por outro motivo que, sem maiores problemas ou constrangimentos, a grande maioria dos brasileiros é capaz de tecer comentários sobre como os povos orientais são "diferentes de nós, ocidentais" e que "o Brasil tem um povo diferente do europeu, mais humano, mais quente", e daí por diante. Essa tensão fundamental fornece a problemática que grande parte do pensamento social brasileiro 
tentou resolver a partir do uso diverso de modos de pensar eurocêntricos (Bortoluci, 2009; Tavolaro, 2005). A apropriação brasileira de categorias como "personalismo" e "patrimonialismo" não é exatamente um "erro" ou uma "falsidade teórica" que deve ser acusada, ao menos da forma como foi proposta por alguns dos maiores pensadores $\mathrm{da}$ sociedade brasileira, como Sérgio Buarque e Raymundo Faoro. ${ }^{1} \mathrm{O}$ próprio caráter contraditório da experiência social brasileira faz com que o uso dessas categorias seja, ao mesmo tempo, indispensável e, no mais das vezes, insuficiente. Tal insuficiência revela-se de maneira mais grave quando o uso dessas estruturas de referências obscurece um dado fundamental da formação social brasileira, que é o fato de esta ter sido constituída como "sociedade periférica”, sendo essa a forma original e constantemente recolocada de articulação entre o "ser Mesmo" e o "ser Outro".

Os termos problemáticos para a apropriação dessas categorias e formas de pensar foram muito bem formulados por Roberto Schwarz, quando afirmou que

[...] nos países saídos da colonização, o conjunto de categorias históricas plasmadas pela experiência intra-européia passa a funcionar num espaço com travejamento sociológico diferente, diverso mas não alheio, em que aquelas categorias nem se aplicam com propriedade, nem podem deixar de se aplicar, ou melhor, giram em falso mas são a referência obrigatória, ou, ainda, tendem a um certo formalismo (1998, p. 106).

Assim, a estrutura de atitudes e referências eurocêntricas, nas sociedades periféricas, apresenta um estatuto problemático, uma vez que, para revelarem dados fundamentais dessas sociedades, devem passar por uma espécie de "rotação de perspectiva" que desvele as formas como a modernidade, desde a sua formação primeira, articula-se à colonialidade (Brasil Jr., 2008; Quijano, 2000). Tal rotação, realizada por uma série de autores críticos como aqueles que analisamos neste artigo - mas, por certo, não apenas por eles -, é o processo pelo qual aquelas categorias passam a dizer respeito a realidades sociais compreendidas a partir de uma ideia de modernidade que incorpora o aspecto da colonialidade como seu dado fundamental (Quijano, 2000).

No pensamento social brasileiro, poucos autores concentraram-se tão intensamente nesse exercício de reinvenção teórica a partir de uma consideração do caráter periférico da formação social brasileira como aqueles que, de formas diversas, ligaram-se ao chamado Seminário do Capital ou estiveram próximos ao que se costuma chamar de Escola Paulista de Sociologia. Refiro-me, sobretudo, a Fernando Henrique Cardoso, Octavio Ianni, Roberto Schwarz, Fernando Novais e, de forma um tanto distinta, Florestan Fernandes.

A escolha desses teóricos, evidentemente, não exaure o elenco das contribuições brasileiras a esse exercício de reflexão teórica - uma vez que não nos centramos em teóricos fundamentais como Celso Furtado ou em importantes contribuições das últimas décadas, como as de José de Souza Martins, Luiz Werneck Vianna, Francisco de Oliveira e, mais recentemente, Jessé Souza; também, por limites de espaço e dada a estratégia analítica aqui explorada, não podemos nos debruçar sobre os ricos debates acerca da possibilidade de uma ciência social nacional que se deram a partir das reflexóes de um importante autor como Guerreiro Ramos (sobretudo Ramos, 1965) - cujas ideias acerca da colonização epistêmica da produção sociológica nacional, e paulista em particular, mereceria uma série de trabalhos à parte (para isso, ver Maia, 2012; Bariani, 2011). ${ }^{2}$ Contudo, esse recorte é consciente e visa, sobretudo, recuperar uma série de reflexões que se desenvolveram em um momento de intenso vigor crítico e criatividade coletiva interdisciplinar, tanto local quanto mundial. Assim, não se trata aqui de fazer um esboço de história intelectual que leve em conta o cotejo do marxismo paulista com outras tradições do pensamento social brasileiro por mais frutífero que possa ser tal exercício -, ou de fazer uma análise do campo científico e cultural em que se inserem os autores aqui brevemente analisados; nem mesmo se pretende analisar se seus argumentos se sustentam empírica e teoricamente em face da produção acadêmica mais recente. Trata-se de propor uma leitura de temas centrais e de moda- 
lidades de reflexão sobre a modernidade explorados por eles, sob a luz de recentes discussões no interior dos chamados estudos pós-coloniais. Essa leitura, informada pelos problemas teóricos e de política do fazer teórico, aponta possíveis caminhos de diálogo que podem ser experimentados tanto com a obra de autores do pensamento social brasileiro, como para a elaboração de novos programas de pesquisa teóricos e empíricos.

De início, vale lembrar que os "estudos pós-coloniais" não constituem uma escola de fronteiras e princípios bem definidos; trata-se de uma agenda de pesquisa multidisciplinar, crítica da relação entre o colonialismo e diversas dimensões do conhecimento e do poder. Como notaram Sapiro, Steinmetz e Ducournau (2010), podem ser incluídos como pertencentes a essa agenda os estudos pós-foucaultianos da relação entre colonialismo e a "imaginação eurocêntrica" (como o trabalho de Edward Said), análises derridianas de textos coloniais e pós-coloniais (Gayatri Spivak), análises psicoanalíticas de subjetividades coloniais (Homi Bhabha, mas também os trabalhos pioneiros de Frantz Fanon e Albert Memmi), críticas heideggerianas à modernidade ocidental (como nos trabalhos de Timothy Mitchell e Dipesh Chakrabarty). Além desses, podem-se adicionar a historiografia anticolonial de influência gramsciana (representada sobretudo pelo grupo de historiadores "subalternos" indianos, como Ranajit Guha e Partha Chatterjee), algumas tentativas de combinar criativamente o marxismo gramsciano e o pós-estruturalismo francês (como na tradição dos estudos culturais britânicos), além das diversas manifestações críticas regionais que combinaram algumas dessas tendências (destaque, aqui, para a tradição latino-americana, representada por autores como Anibal Quijano e Walter Mignolo) (ver Bortoluci e Jansen, 2013).

Dessa forma, procuro realizar uma leitura desses autores a partir de temáticas recentemente exploradas pela literatura pós-colonial, sobretudo aquela produzida por autores latino-americanos. Por meio do resgate e da reconstrução de temas e categorias centrais do marxismo paulista, este artigo pretende dialogar com recentes contribuiçôes de cientistas sociais brasileiros que apontaram a relevância da crítica pós-colonial para uma releitura da história do pensamento social brasileiro e latino-americano (Costa, 2006; Maia, 2009 e 2011b).

Esses intelectuais aqui analisados estão entre os nomes maiores que compartilharam uma "ambiência criativa" (Bastos, 1999, p. 219) em torno da Faculdade de Filosofia, Ciências e Letras da Universidade de São Paulo (a "Maria Antonia", como até hoje é conhecida), desde o final da década de 1950 até meados da década de 1960. Não há uma denominação precisa que abarque a obra de todos esses autores, nem creio que seja preciso forjá-la. Eles possuem contribuições mais estreitamente ligadas a disciplinas específicas (sobretudo a história, a sociologia e a crítica literária), mas que se comunicam e se complementam a partir de algumas "formas de ver" o desenvolvimento da sociedade brasileira. $\mathrm{O}$ que é relevante, aqui, é apontar os terrenos teóricos explorados pelas principais obras desses autores e a forma como tentaram equacionar o dilema da constituição da sociedade brasileira em suas múltiplas relações com o externo.

Aquela ambiência criativa, de um potencial acadêmico-científico bastante original para o panorama intelectual brasileiro até então, possui dois vetores de origem cruciais. O primeiro é aquilo que se convencionou chamar de Escola Paulista de Sociologia, encabeçada pelo sociólogo Florestan Fernandes (ver Bastos, 1999; Arruda, 2001); o segundo é o Seminário do Capital - um seminário interdisciplinar de que fizeram parte jovens acadêmicos como José Arthur Giannotti, Fernando Henrique Cardoso, Ruth Cardoso, Octavio Ianni, Fernando Novais e Paul Singer e, de forma mais esporádica, Roberto Schwarz, Bento Prado Júnior, Francisco Weffort, Michael Löwy e Gabriel Bollafi (ver Schwarz, 1998; Arantes, 1992; Lahuerta, 2005). Esses dois "ambientes intelectuais" não caminharam juntos o tempo todo: pelo contrário, em seu início, havia uma forte tensão entre a agenda metodológica explorada pelos jovens orientandos de Florestan Fernandes (sobretudo Cardoso e Ianni) e a concepção eclética de sociologia deste mestre (ver Lahuerta, 2005).

Não me proponho, aqui, a tratar especificamente de nenhum desses autores ou "vetores", algo que já tem tratamento detalhado na ampla literatura que se vem somando acerca desse momento 
privilegiado da reflexão social brasileira (ver, por exemplo, Arantes, 1992; Arruda, 2001; Bastos, 1999; Mota, 2008). Centro-me em discorrer acerca das formas como algumas das intuições e abordagens desses autores, sobretudo derivados de um uso crítico e pouco ortodoxo do marxismo, forneceram parâmetros para uma descolonização epistêmica da reflexão sobre a modernidade e o capitalismo brasileiros (Chakrabarty, 2000; Mignolo, 2007). Dito de outro modo, creio que esses autores forneceram importantes contribuiçôes e pistas para uma reflexão crítica sobre a modernidade a partir de sua periferia, desvelando a colonialidade do poder e do saber que lhe é constitutiva (Lander, 2000; Mignolo 2003 e 2007; Quijano, 2000) - de forma que sua importância, sobretudo à luz das recentes questões trazidas pelos estudos pós-coloniais, vão além do caso brasileiro.

\section{As várias formas de uma "intuição nova de Brasil"}

Em importante artigo acerca do Seminário do Capital, Roberto Schwarz aponta que:

[...] a certa altura despontou no seminário uma ideia que não é exagero chamar uma intuiçāo nova do Brasil, a qual organizou os principais trabalhos do grupo e teve repercussão considerável. Sumariamente, a novidade consistiu em juntar o que andava separado, ou melhor, em articular a peculiaridade sociológica e política do país à história contemporânea do capital, cuja órbita era de outra ordem (Schwarz, 1998, p. 105, grifo meu).

A expressão-chave dessa síntese é "intuição nova do Brasil". O surgimento de uma intuição de país em um grupo de estudos que se debruçava sobre $O$ capital não é uma consequência necessária ou trivial, uma vez que o objetivo central do seminário era desenvolver uma "leitura cerrada" da obra orquestrada, segundo seus membros, pela rigidez do intelecto filosófico de Giannotti e ladeada pelas contribuições do Lukács de História e consciência de classe e do Sartre de Questão de método.
Contudo, para além do interesse em Marx, é fundamental perceber que o interesse nesse texto decorre de uma série de disputas a que se aferravam os seus jovens membros. Evidentemente, aqueles eram anos de questionamento para a esquerda no mundo todo: depois de 1953, com a morte de Stalin e a posterior divulgação dos crimes cometidos por seu regime, a volta a Marx significava tanto uma tentativa de autorretificação da esquerda quanto uma afronta à exclusividade exegética do Partido Comunista (Schwarz, 1998). Entretanto, esse drama mundial, no caso do grupo, era filtrado por diversos problemas locais: tanto o "local" brasileiro, em épocas de hegemonia do nacionalismo e do desenvolvimentismo, quanto o "local" da própria Maria Antonia, onde, dado seu relativo isolamento das disputas imediatas da política nacional (ver Arruda, 2001), podia-se pensar em "uma esquerda marxista sem chavão, à altura da pesquisa universitária contemporânea, aberta para a realidade, sem cadáveres no armário e sem autoritarismos a ocultar [...]" (Schwarz, 1998, p. 103). ${ }^{3}$

Esse esforço intelectual de leitura sistemática da obra-prima de Marx adquiria um significado especial dadas as transformações pelas quais passava $\mathrm{o}$ Brasil à época. É crucial perceber que o "Brasil" não era apenas um tema a mais na agenda da maioria dos intelectuais participantes do Seminário. Alguns deles elaboravam, então, suas monografias acerca de temáticas fundamentais da sociedade brasileiraas teses de doutorado de Cardoso ([1962] 2003) e Novais ([1979] 2005a) são testemunhos disso.

Mas, para além dos trabalhos de pesquisa individuais e das preocupações intelectuais e políticas apontadas por Schwarz, Milton Lahuerta sintetiza em três referências teóricas a "agenda local" que fornece o contraponto para a leitura do grupo. $\mathrm{O}$ primeiro é, como já indicado, o próprio Florestan Fernandes (e, sobretudo, o seu Fundamentos empiricos da explicação sociológica, livro fundamental do que poderíamos chamar de primeira fase da sociologia paulista), quanto à sua tentativa de elaborar um método eclético que integrasse as várias tradições sociológicas em um programa ainda fortemente influenciado pelo funcionalismo. $\mathrm{O}$ segundo é o nacional-desenvolvimentismo e as teses dualistas formuladas pela Cepal. Por fim, os membros do Se- 
minário contrapunham-se ao nacionalismo, tanto comunista quanto isebiano, que defendia a primazia política e intelectual da disputa entre nação e antinação naquele momento histórico (Lahuerta, 2005, pp. 162-164). Somando-se a isso, não é exagero apontar que esses intelectuais estavam realizando, mesmo por vias pouco explícitas, um diálogo com a tradição dos "intérpretes" do Brasil, uma vez que também se preocupavam, por caminhos e com métodos diferentes, com o problema da formação da sociedade brasileira (Arantes, 1992; Arruda, 2001, p. 298).

Quanto a estes "intérpretes", a influência de Caio Prado Júnior é primordial e apontada pelos próprios membros do grupo. Schwarz compreende que esse autor é uma exceção dentro do panorama do marxismo no Brasil até então, uma vez que o historiador paulista fugia tanto à vulgata comunista quanto ao habitual uso do marxismo como uma "referência filosófica de espíritos esclarecidos", sem grandes consequências para a vida política ou intelectual do país (Schwarz, 1998, p. 102). Fernando Novais aponta que a obra do historiador paulista é um marco na historiografia brasileira e latino-americana, de alguma forma sugerindo que ela antecede as obras do marxismo "mais criativo e crítico" que estariam sendo produzidas na América Latina nas décadas posteriores (Novais, 1986, p. 24) - inclusive por membros do Seminário.

Novais aponta que Formação do Brasil contemporâneo ([1942] 2008) inaugura a "dialética como método" nas ciências sociais e na historiografia brasileiras. Essa observação é de grande importância, já que a primazia da dialética como método - certamente sob o impacto das considerações de Lukács sobre o "marxismo ortodoxo" (ver Lukács, [1922] 2003, cap. 1) - é marcante em praticamente todos os trabalhos que se nutriram das reflexōes deste seminário. Ela constitui o solo metodológico fundamental para o desenvolvimento daquela "intuição de Brasil" que Schwarz descreveu. Ao utilizarem a expressão "marxismo dialético como método", esses autores sugerem que método e objeto são mutuamente constitutivos. Apenas faria sentido falar-se na primazia do método dialético, uma vez que a própria realidade observada deveria ser apreendida em suas múltiplas manifestações e conexōes de sen- tido, caso se considerasse seu caráter fundamentalmente contraditório. A dialética a que esses autores recorrem, dessa forma, é a lógica imanente dos objetos da experiência sobre os quais eles se debruçam. Portanto, haveria nessa experiência intelectual coletiva uma via de mútua constituição entre uma "intuição de Brasil" e uma ciência social dialética. Talvez essa seja a grande contribuição desses autores à tradição marxista: a dialética, no capítulo brasileiro do marxismo, é avançada em virtude das necessidades impostas pelo próprio objeto contraditório que é o capitalismo periférico em suas múltiplas manifestaçôes sociais e culturais e, particularmente, na forma como ele se realiza no Brasil.

É na introdução a Capitalismo e escravidão no Brasil meridional ([1962] 2003) que o argumento da primazia do método dialético para as ciências sociais é elaborado de forma mais sistemática. Essa complexa introdução se justifica ante o processo que o autor visa abordar - no caso, a constituição e a desagregação da sociedade escravocrata no Rio Grande do Sul. É nesse texto também que as influências que Sartre e Lukács sobre a leitura da obra de Marx realizada no Seminário ficam mais claras, sobretudo no que se refere à posição da ideia de totalidade em uma análise dialética. Totalidade, assim, "pressupõe não apenas a existência de diferenças numa unidade, mas também a existência de 'conexões orgânicas' que explicam, ao mesmo tempo, o modo de inter-relacionamento existente entre as determinaçōes que constituem as totalidades e o próprio processo de constituição das totalidades" (Cardoso, [1962] 2003, p. 29).

Nos termos de Martin Jay (1984), a definição de totalidade fornecida por Cardoso compraz tanto uma "totalidade longitudinal" (a história) quanto "latitudinal" (elucidação das relações contraditórias entre elementos que compõem uma realidade concreta). Dada essa conceituação de totalidade, a função do analista é a reconstrução de "totalidades concretas", ou seja, a busca das mediações pelas quais as determinaçōes imediatas (e por isso abstratas, como a noção de atraso, poderíamos dizer) alcançariam inteligibilidade ao circunscreverem-se em constelações globais (como a formação do capitalismo global e a posição de uma determinada sociedade) (ver Cardoso, [1962] 2003, p. 32). A 
totalidade recomposta pelo método dialético, nessa proposta, não anularia a diferença, de forma que o particular é entendido como diferenciação do geral.

É por esses caminhos que podemos entender melhor por que Caio Prado Júnior é o "intérprete" retomado com maior vigor por esses autores. $\mathrm{O}$ historiador realiza uma espécie de "corte epistemológico" (na expressão posterior de Fernando Novais) ao descrever a formação social brasileira, desde a colonização, tendo em vista o processo mais amplo de expansão comercial europeia. A formação social brasileira é um elemento específico daquela totalidade. É a partir dessa perspectiva mundial (ou seja, para além de um plano meramente nacional) que Caio Prado busca compreender as dimensões da vida social e da economia desenvolvidas na colônia. A ideia de dialética, em Formação do Brasil contemporâneo, materializa-se sobretudo na elaboração das relaçóes entre o todo e a parte, o universal (expansão marítima comercial europeia) e o particular (dimensôes da montagem da colônia) - esta última articulada no conceito de "sentido da colonização" (Prado Jr., [1942] 2008, p. 29).

Com Caio Prado, em síntese, começa-se a formar uma "linhagem" (Brandão, 2007) que entende a formação brasileira a partir de suas relações com o capitalismo global, linhagem de que fazem parte os trabalhos que aqui estão sendo analisados (ver Schwarz, 1998, p. 105). Mais do que uma interpretação inspiradora da história da colonização portuguesa nas Américas, essa linhagem marxista e antieurocêntrica instaura uma forma de enxergar as faces do pretenso "atraso" periférico como momentos da modernidade e não como seu o seu outro. A crítica à modernidade ou ao capitalismo periféricos como momento da crítica à modernidade ou ao capitalismo globais depende, como se vê, de uma consideração das formas de entrelaçamento entre as várias determinações dessa totalidade global (Bortoluci, 2009).

A ruptura da unidade de análise e a atenção para as articulações entre as diversas formas assumidas pelo capitalismo e pela modernidade são marcas fundamentais da obra de todos os autores de que tratamos aqui. Essa modalidade de análise que toma como central a análise das relações universais (capitalismo global) e a particularidade da formação brasileira (estrutura de classes local e dependência) levou a que esses autores evitassem o uso do conceito marxista clássico de "modo de produção", seja em seus textos teóricos ou em suas análises históricas e sociológicas. Com essa ruptura quanto à unidade de análise - que de nacional se torna global - passou a ter mais relevância a compreensão das formas de relação entre as diferentes unidades do que a classificação de cada uma delas em um enquadramento de possibilidades históricas bem definidas.

O filósofo José Arthur Giannotti formulou a questão com o maior nível de abstração, sintetizando de forma bastante exemplar aquilo que seria materializado nas várias análises dos outros membros do Seminário. Em artigo de 1976, Giannotti busca, pelas vias da dialética marxista própria ao Seminário, fornecer uma resposta ao problema dos modos de produção, tão em voga na época.

Giannotti realiza uma crítica geral da definição dos modos de produção como enumeração dos predicados que caracterizariam cada um deles. Ele argumenta que a síntese das várias determinações que sumarizaria um conceito não se faz por essa justaposição de diversos predicados, mas por um processo reflexivo, em que resultados se convertem em pressupostos e vice-versa (Giannotti, 1976, p. 163). Dessa forma, o relevante para o estudo dos modos de produção seria a análise de como "relações de produção, relações sociais mediadas por coisas trabalhadas, se instauram e se mantêm graças a um processo que vem repor sua própria realidade" (Idem, p. 163). É a partir da análise dessas relações de produção que o conceito ganha concretude nas múltiplas manifestações históricas possíveis e, sobretudo, abarcando a diversidade das formas de relação entre particularidades e a totalidade do modo de produção. A consideração da diversidade e das formas de entrelaçamento entre as várias manifestaçōes de uma totalidade concreta, abertas por essa forma de análise, são especialmente relevantes no caso do capitalismo, uma vez que

[...] o capital está pois criando formas de organização do trabalho que não se efetivam sob as estritas condiçõos de extração da mais-valia [...]. Em suma, a circularidade do capital se 
perfaz configurando um círculo de círculos. Até quando estamos autorizados a chamar cada um desses círculos um modo de produção? A pergunta pela denominação perde importância quando se privilegia a lógica da constituição das circularidades (Idem, p. 167).

Essa reorientação na colocação do problema sobre as formas sociais por Giannotti o coloca como ponta de lança na oposição local ao marxismo althusseriano que aportava na América Latina após a publicação dos trabalhos de Althusser (1975) e Poulantzas (1978). ${ }^{4}$ Essa outra variante do marxismo teria seus adeptos no Brasil - que, em alguns casos, não deixaram de polemizar com essa leitura oriunda do Seminário (Escobar, 1975; Pires, 1978), ou que, em grande medida, viram suas obras marginalizadas - como é o caso de Luiz Pereira, que, a despeito da centralidade ocupada no departamento de sociologia da USP após a cassação de Florestan Fernandes e seus discípulos mais próximos em fins dos anos de 1960, jamais impôs uma agenda de pesquisa alternativa àquelas firmadas seja por Florestan Fernandes, seja por Cardoso e Ianni. Em suma, a novidade dessa variante do marxismo elaborada teoricamente por Giannotti é a possibilidade de pensar a diferença social e econômica no interior de um capitalismo e de uma modernidade em expansão, permitindo assim a crítica da modernidade na periferia como um capítulo da própria crítica à modernidade.

Fernando Novais extrai importantes consequências dessa forma de pensar a história brasileira em suas relaçôes com a história do capitalismo mundial, em uma explícita incorporação crítica do trabalho de Caio Prado Júnior a partir dos desdobramentos daquela "intuição de Brasil" que surge no Seminário. Na historiografia e nas ciências sociais brasileiras, o trabalho de Novais Portugal e Brasil na crise do Antigo Sistema Colonial (1979) é aquele que apresenta o mais audacioso argumento acerca do papel fundamental desempenhado pela colonização nas Américas para o desenvolvimento do capitalismo na Europa. É interessante observar que, em suas análises da obra de Caio Prado, Novais tenta demonstrar que aquele historiador haveria "ficado no meio do caminho" em suas con- siderações sobre a forma como a colonização do Brasil se situaria no panorama mundial. A questão, aponta Novais, não deveria se restringir às relações entre o estabelecimento da colônia e a expansão comercial europeia: um passo à frente seria a busca das articulações entre a exploração colonial e a transição do feudalismo ao capitalismo (Novais, 1986, p. 20). O autor trabalha a partir da ideia de "acumulação primitiva" em Marx, buscando uma imagem de conjunto que articulasse o geral (formação do capitalismo) e o particular (formação do Sistema Colonial). O sistema colonial - conjunto de mecanismos e relaçóes efetivas que integra e articula a colonização com as economias centrais europeias - é o componente a partir do qual as várias manifestações da colonização se tornam inteligíveis (ver Novais, [1979] 2005a, p. 70) e a partir do qual se realizaria o "sentido profundo da colonização".

Nessa análise, o tráfico negreiro adquire uma posição central no processo de acumulação primitiva na Europa. Em um sistema montado para promover a acumulação primitiva na metrópole, $\mathrm{o}$ tráfico de cativos africanos, comandado por mercadores europeus, instaura um setor de comércio de grande importância - enquanto, como observa Novais, o aprisionamento de indígenas geraria um mercado apenas interno à colônia. A conclusão é contundente: "Paradoxalmente, é a partir do tráfico negreiro que se pode entender a escravidão africana colonial, e não o contrário" (Idem, p. 105). Assim,

[...] enquanto na Europa dos séculos XVI, XVII e XVIII transitava-se da servidão feudal para o trabalho assalariado, que passou a dominar as relaçôes de produção a partir da revolução industrial, no Ultramar, isto é, no cenário da europeização do mundo, o monstro da escravidão mais crua reaparecia com uma intensidade e desenvolvimento inéditos (Idem, p. 98).

Novais expõe a metrópole se desnudando na colônia: ela - colônia, depois periferia do sistema-mundo capitalista em formação - revela a natureza do processo civilizador europeu. No rastro da tese benjaminiana, o argumento de Novais e os outros trabalhos que desenovelaram aquela intuição de 
Brasil procuraram mostrar que a história da formação da periferia é o documento de barbárie sem o qual não se entende o documento de civilização composto desde a Idade Moderna. Em termos contemporâneos, a colonialidade revela as verdades da modernidade em constituição (Mignolo, 2000). O ponto de vista periférico permite uma estrutura de referências segundo a qual as "anomalias" periféricas expõem as fraturas constitutivas da "normalidade moderna". O trabalho do historiador ajuda a construir coletivamente uma história do Brasil que não é mais nacional, uma vez que o eixo de análise é internacional. Trata-se, nas palavras de Paulo Arantes, de um verdadeiro exercício de "desprovincialização da história do país" (Arantes, 1992, p. 89) algo bastante anterior, mas inteiramente coerente, à proposta de revisão histórica proposta por um crítico pós-colonial como Dipesh Chakrabarty (2000) e afinado com uma consideração contemporânea da colonialidade da modernidade (Mignolo, 2007; Mitchell, 2000).

Para além disso, Novais esboça uma preocupação que também estaria presente nas principais obras de Cardoso e nos "estudos de dependência" por ele encabeçados: o historiador preocupa-se, em diversos momentos, em mostrar que a acumulação realizada pela exploração colonial não é suficientemente captada por uma ideia de "exploração da colônia pela metrópole": é preciso identificar uma camada social específica que se beneficiaria do processo - a burguesia mercantil -, assim como na colônia haveria uma camada que se beneficiava da participação no sistema colonial - o senhorio o (Novais, 2005b). Novais descreve a montagem de uma economia colonial mercantil, escravista e com acumulação externa (ver Novais, 2005a, p. 145), mas observando que existem grupos sociais que se beneficiam assimetricamente dessa acumulação primitiva em processo.

\section{Elementos de uma sociologia periférica}

Os diversos aspectos que Novais desenvolve na análise do sistema colonial seriam, também, em grande medida, as balizas para as análises sociológicas de Cardoso e Ianni, desenvolvidas paralelamen- te ao trabalho do historiador, naquilo que alguns autores chamaram de "sociologia da dependência". 5 Voltada para os problemas do desenvolvimento econômico e social de seu tempo, a obra desses sociólogos pode ser entendida, sobretudo, como uma tentativa de compreensão das formas pelas quais o desenvolvimento repõe as relações sociais forjadas pela situação colonial. Em outros termos, essa "sociologia da dependência", de forte inspiração dialética, volta-se à realização de um programa crítico de compreensão da especificidade das formações periféricas pós-coloniais - especialmente latino-americanas - e dos potenciais bloqueios ao desenvolvimento derivados dessa posição específica no capitalismo mundial. ${ }^{6}$

Os estudos que constituíram esse programa sociológico crítico trataram dos mais diferentes aspectos do desenvolvimento dessas sociedades, como que compondo uma interpretação coletiva do desenvolvimento das sociedades dependentes latino-americanas e, mais especificamente, da brasileira. Pode-se pensar que essa "interpretação coletiva", de fronteiras pouco definidas, presente na obra desses sociólogos - mas também na história colonial de Novais e nos estudos literários de Roberto Schwarz como as várias materializaçōes daquela "intuição de Brasil” gerada no Seminário do Capital e gestada nos vários espaços intelectuais e acadêmicos que perfaziam aquela "ambiência criativa" a que já nos referimos.

Um exemplo dessas várias materializações é o estudo de Octavio Ianni sobre o papel do Estado no desenvolvimento do capitalismo industrial brasileiro. Conforme se poderia esperar, dadas as suas referências teóricas e o enquadramento que foi aqui destacado até o momento, a análise da industrialização brasileira realizada por Ianni busca a construção da totalidade dos processos - tanto do próprio capitalismo em sua expansão desigual e combinada quanto das várias transformaçôes por que a sociedade brasileira passava desde o início do século XX. $\mathrm{O}$ que há de mais interessante em termos metodológicos na abordagem de Ianni é a sua tentativa de mostrar como as dualidades historicamente mobilizadas para a compreensão da modernização brasileira não davam conta da constituição da concretude desse processo. Ianni, dito de outro modo, 
não analisa apenas as formas de interpenetração entre "arcaico" e "moderno" próprias à modernização em uma sociedade periférica como a brasileira. "O conceito de dualidade retira a historicidade da história, tomando o objeto presente em sua existência manifesta" (Ianni, [1965] 2004, p. 73, grifo meu); sua crítica busca atingir um alcance maior a respeito do uso de uma lógica dualista na compreensão desse processo. ${ }^{7}$

Essa desconstrução de polaridades abstratas estará presente em todos os trabalhos aqui referidos, desde Capitalismo e escravidão no Brasil Meridional. Nesse livro, publicado em 1962, Cardoso já avança em seu programa crítico, ao mostrar exatamente as formas de integração de elementos que, vistos a partir de uma narrativa eurocêntrica da história, seriam incompatíveis. O livro já constitui uma primeira tentativa interna ao grupo de mostrar como escravidão e capitalismo não são incompatíveis por princípio, sendo que o segundo precisou da primeira para desenvolver-se - uma consideração que desvela uma "história outra do capitalismo", só apreensível a partir das margens desse sistema.

A dimensão sociológica daquela dialética encontrará máxima expressão no trabalho de Fernando Henrique Cardoso, do início da década de 1960 até meados da década de 1970. Em suas análises sociológicas mais densas, é possível perceber uma constante preocupação com a reconstituição de totalidades concretas, referidas historicamente. Esta característica não advém somente daquela leitura coletiva da obra de Marx, mas também constituiu uma preocupação geral de grande parte da "sociologia paulista" mobilizar outros autores e tradições teóricas para além do marxismo, como reflexões de Weber e os trabalhos da Cepal.

Alguns dos principais trabalhos de Cardoso podem ser lidos como uma tentativa geral do questionamento de categorias e pressupostos históricos forjados em um contexto europeu para a compreensão das dinâmicas sociais em países periféricos. O trabalho Empresário industrial e desenvolvimento econômico no Brasil é exemplar nesse aspecto. Nele, Cardoso realiza aquela que talvez seja a mais importante crítica acadêmica à ideia da existência de uma "burguesia nacional" no Brasil, esta entendida como um setor social preocupado em promover o desenvolvimento e a industrialização em bases nacionais, em oposição à posição das oligarquias agrárias, aliadas permanentes do capital internacional. Cardoso tem em mente uma série de alvos, desde o Partido Comunista (participante de uma espécie de aliança desenvolvimentista), o Iseb (por seu nacionalismo e pela tentativa de elaborar uma análise sociológica do Brasil como se ele fosse um "fato singular discreto" - conforme Cardoso, [1964] 1972, p. 47), até a sociologia da modernização, sobretudo como proposta por W. W. Rostow, com suas etapas de desenvolvimento bem definidas e sua proposição de articulações e papéis sociais descolados de contextos históricos.

Em vez de utilizar esses modelos abstratos e pretensamente universais, próprios a essas teorias sociológicas em voga em seu tempo (incluindo a sociologia de Parsons), Cardoso propõe que se avance na reconstrução de situações concretas, uma reconstrução que exige a reflexão acerca das estruturas que explicariam o desenvolvimento e que condicionariam a passagem de um tipo de dinâmica a outro. ${ }^{9}$ A constituição dessas totalidades concretas exige uma consideração - e estamos aqui em terreno conhecido - das relaçóes entre componentes estruturais internos e externos. Dessa forma, ganharia significado mundial as noções de "atraso" ou, mais especificamente, de subdesenvolvimento: "A noção de sociedade subdesenvolvida só se torna significativa quando há uma referência implícita a uma relação determinada entre um tipo particular de sociedade com outra que é 'desenvolvida" (Cardoso, [1964] 1972, p. 73). Essa relação determinada passa por uma análise, conforme afirma Cardoso, da divisão internacional do trabalho e do tipo de dominação que lhe é correlato, e por uma consideração do subdesenvolvimento como uma forma do desenvolvimento: "É preciso, pois, partir da análise das relações básicas entre essas duas formas de sociedade que, em conjunto, exprimem o modo capitalista de produção para compreender cientificamente o processo de desenvolvimento no 'mundo ocidental'" (Idem, ibidem).

Assim, particularmente quanto ao objeto de que trata nessa pesquisa, Cardoso lembra que a análise da burguesia no Brasil deve ater-se às espe- 
cificidades do desenvolvimento de uma economia periférica, onde o empreendedor não repetiria a via "clássica" de formação do capitalismo; além disso, o potencial desse desenvolvimento seria condicionado pela situação do mercado mundial e pelos níveis desiguais de desenvolvimento técnico (Idem, p. 46). A consideração dessa especificidade leva a consequências analíticas e políticas extremamente distintas daquelas que Cardoso pretende criticar.

$\mathrm{O}$ argumento que vai sendo revelado pelo sociólogo é o de uma espécie de "drama periférico", em que modernidade e atraso se articulam de formas diversas em todas as fases da "modernização". O que se expõe, particularmente, é a inadequação da categoria de uma burguesia nacional: essa "camada", de que se esperava tanto, aliava-se, sempre que preciso, com os setores agrários e oligárquicos mais "arcaicos" ou com o capital internacional, sem que, na prática, isso fosse sinal de qualquer grande contradição. Pelo contrário: na sociedade brasileira, conviveriam valores estamentais e de classe - não ladeados de forma dualista, mas compondo, por uma simbiose estrutural, a modernidade brasileira. Cardoso demonstra, poderíamos dizer, a dissolução das categorias mesmas de "tradicional" e "moderno", vistas a partir do capitalismo periférico: "À crescente expansão do mercado e, consequentemente, ao aumento de poderio econômico da burguesia industrial, não tem seguido, pelo menos no mesmo ritmo, a desagregação da antiga ordem político-social pré-industrial. A burguesia industrial se acomoda em larga medida à dominação tradicional" (Idem, p. 181).

Este trabalho de Fernando Henrique Cardoso firma grande parte das bases daquilo que irá se constituir, nos anos seguintes, como uma das versões da "teoria da dependência" - ou dos "estudos de dependência", como prefere Cardoso (1979 e 1977). O principal livro que marca esses estudos, Dependência e desenvolvimento na América Latina ([1969] 2004), escrito conjuntamente com o economista chileno Enzo Faletto, parte de considerações e pressupostos metodológicos que guardam grande proximidade com o Empresário industrial..., seja na crítica à sociologia da modernização, na desconstrução de perspectivas dualistas e da transposição das análises sobre o "capitalismo clássico" para a análise de sociedades periféricas, seja na compre- ensão integrada do desenvolvimento das economias centrais e periféricas, tendo em vista sobretudo as formas como se instituem estruturas de dominação internas e externas aos Estados dependentes. Este último é um aspecto bastante relevante do trabalho de Cardoso, que diferencia sua obra daquela dos principais autores "dependentistas" que produziam seus principais trabalhos no mesmo período nos Estados Unidos - sobretudo André Gunder Frank, a quem Cardoso dirige críticas duríssimas (Cardoso, 1977). A estrutura de composição da totalidade das relações sociais que caracteriza as situações de subdesenvolvimento exige, para ele, não apenas um tratamento da posição de um determinado país no mercado mundial, mas, sobretudo, da dinâmica de classes interna e externa que constituiu e que garante a manutenção dessa situação de dependência. $\mathrm{Na}$ maior parte desse livro, Cardoso e Faletto dedicam-se a estudar as modificações das estruturas de dominação que garantem o desenvolvimento desses Estados em diferentes períodos.

Com essa consideração das relações contraditórias entre grupos internos e externos, a vertente dos "estudos da dependência" procura realizar uma espécie de atualização das análises marxistas clássicas do imperialismo para o período em que as economias periféricas passam por um processo de industrialização ou já se industrializaram em alguma medida (ver Cardoso, 1979, p. 133). Mas uma atualização que dedica atenção especial para as dinâmicas internas aos Estados periféricos - algo que só é tratado marginalmente em trabalhos como os de Lênin, Hilferding ou Rosa Luxemburgo (Cardoso, 1977 , p. 13).

Em "Classes sociais e história: considerações metodológicas", Cardoso propõe uma importante síntese sociológica das leituras da realidade periférica, particularmente brasileira, que animaram os diversos trabalhos a que nos referimos aqui. Nesse artigo, Cardoso apresenta uma espécie de revisão dos desafios que a consideração da realidade periférica coloca aos mais diversos aspectos da teoria sociológica e, diríamos, para a teoria da história que orienta os principais esforços de teorização dessa disciplina.

O exercício teórico realizado por Cardoso nesse artigo pode ser lido como uma demonstração sociológica da colonialidade da modernidade 
capitalista, a partir de uma perspectiva periférica. Cardoso esforça-se por mostrar que a compreensão de uma determinada realidade histórica e, particularmente, do modo de produção capitalista exige atenção para as formas como os diversos elementos organizam-se em um todo particular: "É preciso mostrar, simultaneamente, que a periferia não existe sem o centro e que este - desde que exista um modo de produção colonial - é também este modo de produção que, por outro lado e ao mesmo tempo, é oposto ao modo capitalista industrial de produção. É e não é, como se propõe na lógica dialética" (Cardoso, 1975, p. 106).

Esta realização periférica específica do capitalismo - que, como também aponta Giannotti, só pode ser entendido como um modo de produção subsidiário (modo de produção colonial, por exemplo) caso se mostre sua articulação interna ao modo de produção capitalista que o engloba - permite a compreensão da escravidão na periferia, mais uma vez - e não por menos, dada a significação do problema para a formação social brasileira -, ou a posição social dos senhores de escravos como problema próprio ao capitalismo e à modernidade. A análise que Cardoso faz deste setor da sociedade escravista brasileira é digna de nota, uma vez que demonstra a contradição como forma de ser fundamental de uma sociedade periférica. O sociólogo aponta que esses senhores de escravos constituíam uma categoria social cuja existência presumia a contradição entre as formas sociais de trabalho próprias à produção colonial e o destino mercantil dos resultados dessa produção - uma contradição derivada do modo como se inseriam no sistema capitalista mundial: "Demônios bifrontes, se se quiser, duplamente contraditórios, excrescências necessárias para o avanço, no centro do sistema, da acumulação e da potenciação das forças produtivas; entraves estruturais para a etapa seguinte do desenvolvimento gerado pela acumulação que eles em parte propiciaram” (Idem, p. 111).

\section{Literatura, modernidade e crítica na periferia}

Para vislumbrarmos outras dimensōes desse programa crítico interdisciplinar, é preciso ter em conta que esse tipo de contradição próprio às formas de efetivação de classes sociais e da própria experiência social na periferia seria explorado por Roberto Schwarz, sobretudo em sua análise clássica das obras de Machado de Assis (Schwarz, [1977] 2000a e [1990] 2000b). Como aponta Paulo Arantes (1992), Schwarz tira consequências estéticas daquela "intuição de Brasil", podendo desenvolver uma importante leitura dialética da vida cultural brasileira no século XIX, ${ }^{10} \mathrm{em}$ grande comunicação com as análises históricas de Novais e com as descobertas sociológicas de Cardoso e Ianni - sem nos esquecermos de sua companheira de "sociologia paulista", Maria Sylvia de Carvalho Franco (1983). A tese que se desenvolve coletivamente, que trata do caráter funcional do "atraso" na reprodução da sociedade moderna na periferia e seus desdobramentos no caso brasileiro, é tomada por Schwarz como ponto de partida para uma crítica cultural desprovincializadora, uma vez que ela permitiria inscrever na ordem internacional aquilo que parecia nos afastar dela. Ou seja, a partir daquele diagnóstico acerca do travejamento sociológico das sociedades periféricas em relação à modernidade capitalista global, o crítico busca resolver a antinomia há muito presente nos debates culturais no país, que colocava ao crítico uma espécie de escolha entre nacionalismo ("tudo nos seria original") e cosmopolitismo ("tudo aqui é cópia").

Schwarz propõe uma certa modalidade de análise dialética da cultura brasileira. Para isso, além de avançar um diálogo e apropriaçōes do que ele chama de "tradiçãao contraditória" (Lukács, Brecht, Benjamin e Adorno, além da inspiração do próprio Marx), Schwarz busca uma filiação com o método de Antonio Candido, sobretudo presente em sua análise clássica do romance Memórias de um sargento de milícias (1854), de Manuel Antonio de Almeida. Em "Dialética da malandragem" (1970), Candido teria inaugurado, no juízo de Schwarz (ver [1987] 2006), a análise dialética da cultura no pensamento brasileiro; o procedimento fundamental que vem de Cândido é a investigação da "função exercida pela realidade social historicamente localizada para constituir a estrutura da obra - isto é, um fenômeno que se poderia chamar de formalização ou redução estrutural dos dados externos" (Candido, 1970, p. 75 , grifo meu). Schwarz adverte que a 
crítica inaugurada por Candido no Brasil parte de uma não separação entre o estético e o social, uma vez que a forma é entendida como síntese do movimento histórico. Dessa maneira, a análise da cultura passa a ser mecanismo de elucidação da estrutura social, assim como as ciências sociais e a história iluminam a apreensão da forma pelo crítico.

Esse método de crítica cultural seria levado a cabo, de forma mais acabada, na importante leitura que Schwarz faz do livro Memórias póstumas de Brás Cubas (1880), de Machado de Assis. Em Um mestre na periferia do capitalismo ([1990] 2000b), Schwarz descreve minuciosamente as maneiras como Machado de Assis teria erigido a "volubilidade" (tanto na prosa quanto no enredo) como forma organizadora desse romance. Volubilidade revelada, por exemplo, pelas mudanças sucessivas de tom e opinião do narrador e pela sua circulação no interior da sociedade brasileira do século XIX. O mais relevante para nossas observações aqui é mostrar como Schwarz consegue compor um Machado de Assis crítico das relações sociais do Brasil de sua época, uma vez que esse princípio formal da volubilidade se relaciona à forma de ser da burguesia brasileira no século XIX, funcionando a partir de um código de ética que compunha norma burguesa e favor, ou liberalismo e escravismo. A volubilidade é a forma que Machado encontra de representar uma situação em que as ideias liberais não se podiam praticar, mas ao mesmo tempo eram indesatáveis (Idem, p. 25).

A volubilidade seria, portanto, uma maneira de reduzir formalmente o antagonismo de classes em sua forma particular ao Brasil (Idem, p. 62) - ou seja, um país periférico em que, pelo mecanismo do "desenvolvimento desigual e combinado do capitalismo", a causa última de sua formação social "absurda" "está nos avanços do capital e na ordem planetária criada por eles, de cuja atualidade as condutas disparatadas de nossa classe dominante são parte tão legítima e expressiva quanto o decoro vitoriano" (Idem, p. 39, destaque no original). Não é exagero apontar que o termo "atualidade", destacado por Schwarz, remete aos problemas tratados por autores pós-coloniais acerca da temporalidade global de uma história narrada a partir das margens, como Homi Bhabha (1998), Boaventura de Sousa
Santos (2006 e 2007) e Timothy Mitchell (2000). Dessa maneira, a construção literária pode ser enxergada como um instrumento de crítica global da modernidade, vista de suas margens:

Machado de Assis pormenorizava e apurava a dimensão não burguesa da existência burguesa no Brasil, e estendia ao âmbito da convenção artística, na forma generalizadora da transgressão [...]. Em consequência, escravismo e clientelismo não são fixados apenas pelo lado óbvio, do atraso, mas também pelo lado perturbador e mais substantivo de sua afinidade com a tendência nova (Schwarz, 2000a, pp. 185-186).

A crítica de Machado, via Schwarz, adquire dimensões de crítica ao capitalismo moderno global, em suas múltiplas realizações; dito de outra maneira, Schwarz, informado pelo diagnóstico sociológico de que vim tratando (e, evidentemente, ampliando-o), propõe a leitura de Machado de Assis como um crítico não apenas de nossas elites oitocentistas, mas, a partir delas, do próprio universalismo burguês, que nos países periféricos teriam suas "horas de verdade" (Idem, p. 217). Pelas vias da volubilidade, avançar-se-ia em direção a uma desprovincialização do Brasil, uma vez que são os mecanismos desiguais de inserção do país nos meandros do capitalismo global que dariam sentido aos comportamentos de classe exemplificados por Brás Cubas, um típico representante da elite brasileira do período. Contudo, fazer sentido da ação dessa burguesia local exige uma consideração sobre as articulações globais que configuraram a forma de ser colonial e pós-colonial brasileira; por esses caminhos, localizar o Brasil no Ocidente passa por emitir um outro olhar sobre esse Ocidente, a partir dessa experiência periférica.

No controverso artigo "Ideias fora do lugar", Schwarz já indicava a peculiaridade da formação cultural brasileira: apenas nos reconheceríamos por essa espécie de "torcicolo cultural" ([1977] 2000a, p. 25); isso quer dizer que a análise do local só se efetiva com a análise e a crítica do global: "para analisar a originalidade nacional, sensível no dia a dia, fomos levados a refletir sobre o processo de colonização em seu conjunto, que é internacional. $\mathrm{O}$ 
ficta das conversóes e reconversões do liberalismo e favor é o efeito local e opaco de um mecanismo planetário" (2000a, p. 30). Esse artigo, que vem sendo objeto de debates até hoje (ver, por exemplo, Franco, 1983; Bosi, [1982] 2000; Ricupero, 2008), só ganha sentido quando lido à luz da obra posterior de Schwarz e do contexto intelectual que forneceu aquela "intuição de Brasil", a partir da qual ele lança o olhar sobre a cultura brasileira.

Por essa lente, Machado de Assis se revela como um "autor pós-colonial" exemplar, e Schwarz, no mesmo sentido, um crítico igualmente pós-colonial. Isso não passou despercebido para a recente literatura pós-colonial latino-americana: Walter Mignolo aponta para a complementaridade entre a crítica de Frantz Fanon e de autores como Antonio Candido, Roberto Schwarz e Silviano Santiago, estes especificamente no terreno da crítica cultural. Apesar das evidentes diferenças entre estes autores, Mignolo afirma que todos eles buscaram, à sua maneira, construir novos centros de enunciação a partir de suas localidades geo-históricas (Mignolo, 2005, pp. 189-190). Através da leitura de Machado de Assis, Schwarz expressaria uma forma de conceber a cultura (e, ao mesmo tempo, a sociedade) a partir de uma política e de uma sensibilidade geo-historicamente marcadas, ou seja, pela condição da modernidade na periferia em seu entrelaçamento com o capitalismo mundial.

É de se observar, contudo, que Schwarz pode ser lido de forma ainda mais produtiva de uma perspectiva pós-colonial caso se situe sua observação sobre a coexistência de escravidão e liberalismo no Brasil em um panorama global. Como observa Losurdo (2011), tal coexistência teve vida em diversos contextos políticos e socioeconômicos, seja na manutenção da escravidão em uma série de colônias europeias até meados do século XIX, seja nos apoios explícitos ou velados à escravidão por parte de autores liberais clássicos, como Locke e Tocqueville. Dessa forma, essa torção entre ideias e sua efetividade histórica parece caracterizar a própria condição de realização da modernidade em um contexto global marcado por brutais desigualdades problema que também não passou despercebido a autores latino-americanos como Enrique Dussel (2000) e Anibal Quijano (2000).

\section{Considerações finais}

Em um trabalho bastante polêmico, o historiador indiano Dipesh Chakrabarty, ligado à corrente conhecida como "estudos subalternos", buscou demonstrar que, no discurso histórico tradicional, a Europa é a soberana de "todas as histórias" mesmo da história "da Índia", "da China” ou de qualquer outra sociedade não europeia. Chakrabarty articula, com esse raciocínio, uma contundente provocação, de forma bastante consciente. O historiador aponta uma tendência de que todas essas histórias nacionais particulares se tornem variações de uma narrativa mestra - a própria narrativa da história da Europa -, que alocaria cada uma dessas histórias nacionais em uma posição de subalternidade (Chakrabarty, 2000, p. 27). O problema fundamental refere-se às formas de pensar que orientam a narrativa da modernidade (e das possibilidades da "transição" a ela), a partir das quais cada uma das histórias nacionais é investigada. Nesse sentido, apenas a história da Europa, aquela narrativa mestra a que se refere Chakrabarty, seria passível de formulação teórica - todas as outras seriam apenas variaçôes e fracassos, adicionando cor e forma ao esqueleto da história europeia (Idem, p. 29). Chakrabarty parece corroborar as consequências de uma afirmação que atravessa a história do pensamento social em nações periféricas: não teríamos sido contemplados pelos clássicos - a não ser, poderíamos dizer, como formas diversas de habitar o polo negativo das dualidades que orientaram a reflexão sobre a modernidade, que teria a Europa (ou o Ocidente) como sujeito.

Contudo, o pensamento social brasileiro, em inúmeros momentos, mostra que as leituras sobre sociedades periféricas derivadas de alguma forma de apropriação daquela estrutura de atitudes e referências inicialmente eurocêntricas não são mentiras grosseiras, falsificaçōes elementares do real ou concepções pré-científicas acerca da história dessas sociedades. Trata-se de um conjunto de imagens, como vimos, ao mesmo tempo "indispensável" e não é por menos que ele é mobilizado nos mais diversos contextos periféricos e pós-coloniais - e "insuficiente", sobretudo por não se ater aos elementos de dominação de classe e ao caráter perifé- 
rico da formação dessas sociedades. Dessa maneira, procurou-se mostrar que essas imagens acerca do "atraso" ou do caráter periférico da formação social brasileira ganham maior relevância analítica e crítica a partir de uma espécie de redefinição da unidade de análise, possibilitando uma reestruturação categorial que abra espaço para que a crítica à modernidade periférica constitua uma crítica à modernidade global. Em síntese, pode-se observar no interior desses trabalhos uma série de movimentos críticos que também estiveram presentes em outros momentos de nossa história intelectual e que hoje são retrabalhados por autores pós-coloniais: um questionamento da falsa identidade entre as ideias de modernidade e de Ocidente; a provincialização da experiência europeia; a proposta de uma visada macrorrelacional na análise de dinâmicas sociais; e a tentativa de escrever a história da modernidade a partir de sua periferia (ver também Bortoluci e Jansen, 2013).

Isso não é o mesmo que dizer que todas as preocupações levantadas pelos estudos pós-coloniais estiveram presentes nos trabalhos aqui analisados. Para citar apenas uma temática crucial, é notável a ausência de uma análise mais detida desses autores sobre as populaçóes, os saberes e as tradiçóes indígenas brasileiras, ou mesmo uma incorporação crítica da história da violência colonial contra essas populações ao aparato teórico e histórico por eles esboçado. Essa ausência se torna mais gritante para leitores de nossos dias em face da relevância do tema na reflexão intelectual e na política contemporânea, sobretudo devido às recentes mobilizações no continente lideradas por populações indígenas, que assumiram dimensões diversas e recolocaram inúmeros problemas acerca da forma como a modernidade, o capitalismo e o desenvolvimento se processam em terras latino-americanas.

Consideradas essas limitações, as manifestações desse marxismo paulista ainda demonstram a possibilidade de uma superação criativa dessa narrativa mestra eurocêntrica - certamente não a única experimentada em nosso pensamento social. Nos campos da crítica da cultura, da economia política, da história colonial e da sociologia, avançaram-se demonstrações e ensaios do potencial crítico daquela intuição de Brasil aventada a partir de uma leitura conscientemente periférica da teoria marxista. Intuição que, em essência, é uma forma de pensar uma crítica pós-colonial à modernidade capitalista a partir de sua periferia - e que ganha ainda novos sentidos ante as discussóes correntes acerca de um projeto coletivo de ciências sociais e humanas pós-coloniais.

\section{Notas}

1 Jessé Souza (2000 e 2003) mostra ainda como o uso dessas leituras do país ajudou a configurar uma ideologia conservadora que persiste até hoje, que tende a desvincular os elementos de "atraso" (ou as nossas mazelas sociais mais graves) das formas como se organiza a estratificação social brasileira, típica de uma sociedade periférica. Em outros termos, essa apropriação teórica esconde, ao mesmo tempo, os elementos de dominação de classe e o caráter periférico de nossa formação social.

2 Maia (2011a), ao se debruçar sobre o trabalho de Guerreiro Ramos em perspectiva comparada ao sociólogo malaio Hussein Alatas, mostra como é promissora a estratégia analítica de ampliar as fronteiras de estudo do pensamento social brasileiro a partir da comparação com autores inseridos em contextos nacionais que apresentam problemas semelhantes aos enfrentados por autores brasileiros. Vale notar que o trabalho de Maia dá continuidade a outros trabalhos pioneiros que já haviam sugerido comparaçôes semelhantes entre Guerreiro Ramos e outros intelectuais pós-coloniais (Motta, 2000 e 2010; Ortiz, 1985).

3 Alfredo Bosi aponta que essa articulação entre ciências sociais e dialética é sinal de uma desconfiança desses estudantes críticos contra a aliança entre técnica pretensamente neutra e opressão ideológica que marcava os esforços de desenvolvimento do país à época e que, em termos metodológicos e teóricos, haviam povoado o ensino de ciências sociais no país com receitas positivistas e funcionalistas - uma questão de "política cultural vivida por toda uma faixa de cientistas sociais que pretendem fazer do seu conhecimento um instrumento eficaz de transformação" (Bosi, [1992] 2000, p. 313).

4 Ver Giannotti (1977); em linha semelhante, ver Cardoso (1971). Para uma um contraste entre as duas perspectivas, ver Love (1998). Saes (2007) e Quartim de Moraes (1984) elaboraram as principais críticas brasileiras de uma perspectiva althusseriana ao traba- 
lho de Giannotti, buscando mostrar como a leitura de Marx proposta por Giannotti não resolve os problemas apontados por ele no trabalho de Althusser.

5 As relaçôes entre os estudos da dependência e a análise histórica de Novais não deixaram de ser notadas pelos críticos desta, como se observa exemplarmente no trabalho de Flamarion Cardoso (1980).

6 É bem sabido que essa não é a única versão brasileira da teoria da dependência, algo que fica evidente com a leitura de autores como Theotônio dos Santos (1970), Vânia Bambirra (1974) e Ruy Mauro Marini (1973). Como se depreende facilmente da leitura deste artigo, não me parece correta a comum distinção entre a tradição weberiana (que seria representada principalmente por Cardoso e Faletto) e uma tradição marxista (composta pelos três autores citados acima, além de outros importantes nomes estrangeiros, como André Gunder Frank). Trata-se, pelo contrário, de uma tensão no interior do próprio marxismo, apesar de Cardoso e Faletto também incorporarem outras tradições teóricas, como os estudos da Cepal e a sociologia weberiana. A comparação entre essas tradições encontra vasto tratamento na literatura (Santos, 1998; Cardoso e Serra, 1978; Palma, 1981; Bresser Pereira, 2010). O que vale aqui ressaltar é que os estudos de Cardoso comumente associados a essa tradição são herdeiros desse duplo movimento que procuramos caracterizar aqui: por um lado, uma nova intuição de Brasil em sua relação com o desenvolvimento capitalista global; por outro, uma forma de marxismo pouco preocupada com uma caracterização das especificidades dos modos de produção e mais focado na reconstrução de totalidades sociais concretas.

7 Vale lembrar que a crítica ao dualismo seria ainda desenvolvida em trabalhos posteriores de grande importância, sobretudo em Crítica à razão dualista, de Francisco de Oliveira, e Cativeiro da terra, de José de Souza Martins (ver Arantes, 1992, e Viotti da Costa, 1978).

8 Para um exemplo fundamental, ver a análise de Martins sobre a formação agrária brasileira, sobretudo em Martins (2004); para uma análise geral desta questão, ver Bastos (1999).

9 Como explica em artigo posterior, essa passagem para a concretude exige a substituição de modelos de análise baseados em determinaçôes gerais e abstratas por outro que vise a situar concretamente cada momento significativo de modificação da produção capitalista internacional, mostrando como se dá a rearticulação das classes sociais, da economia e do Estado em situações particulares (Cardoso, 1979, p. 127).
10 E também do século XX, como atesta, por exemplo, sua importante análise da cultura brasileira nos primeiros anos da ditadura militar (ver Schwarz, [1969] 2008).

\section{BIBLIOGRAFIA}

ALTHUSSER, Louis. (1975), Ler o Capital. Rio de Janeiro, Zahar.

ARANTES, Paulo E. (1992), Sentimento da dialética na experiência intelectual brasileira. São Paulo, Paz e Terra.

ARRUDA, Maria A. do N. (2001), Metrópole e cultura: São Paulo no meio século XX. Bauru, SP, Edusc.

BAMBIRRA, Vania. (1974), El capitalismo dependiente latinoamericano. México, Siglo Veintiuno.

BARIANI, Edison. (2011), Guerreiro Ramos e a redenção sociológica: capitalismo e sociologia no Brasil. São Paulo, Editora da Unesp.

BASTOS, Elide Rugai. (1999), "Pensamento social da Escola Sociológica Paulista", in S. Miceli (org.), O que ler na ciência social brasileira, 1970-1995. São Paulo, Sumaré/Anpocs, vol. 4.

BHABHA, Homi K. (1998), O local da cultura. Belo Horizonte, Editora da UFMG.

BORTOLUCI, José H. (2009), "Para além das múltiplas modernidades: eurocentrismo, modernidade e as sociedades periféricas". Revista Plural, 16 (1): 53-80.

BORTOLUCI, José H. \& JANSEN, Robert. (2013), "Toward a postcolonial sociology: the view from Latin America". Political Power and Social Theory, 24:199-229.

BOSI, Alfredo. ([1992] 2000), Dialética da colonização. São Paulo, Companhia das Letras.

BRANDÃO, Gildo M. (2007), Linhagens do pensamento politico brasileiro. São Paulo, Hucitec.

BRASIL JR., Antonio da S. (2008), "Demora cultural, dilema social e capitalismo dependente: rotaçôes de perspectivas". Trabalho apresentado no Congresso do Projeto Temático Linhagens do Pensamento Político Brasileiro, FFLCH-USP.

BRESSER PEREIRA, Luiz Carlos. (2010), "As três interpretações da dependência”. Perspectivas, 38: $17-48$. 
CANDIDO, Antonio. (1970), "Dialética da malandragem". Revista do Instituto de Estudos Brasileiros, 8: 67-89.

CARDOSO, Ciro Flamarion S. (1980), "As concepções acerca do 'sistema econômico mundial' e do 'antigo sistema colonial': a preocupação obsessiva com a 'extração de excedente'", in J. R. do Amaral Lapa (org.), Modos de produção e realidade brasileira, Petrópolis, Vozes.

CARDOSO, Fernando H. ([1962] 2003), Capitalismo e escravidão no Brasil meridional. São Paulo, Civilização Brasileira. . ([1964] 1972), Empresário industrial e desenvolvimento econômico. São Paulo, Difel. (1971). "Althusserianismo ou marxismo? A propósito do conceito de classes em Poulantzas". Estudos Cebrap, 3: 66-85. (1973). O modelo político brasileiro e outros ensaios. São Paulo, Difel.

(1975). Autoritarismo e democratização. Rio de Janeiro, Paz e Terra. . (1977). "The consumption of dependency theory in the United States". Latin American Research Review, 12 (3): 7-24.

(1979). “'Teoria da dependência' ou análises concretas de situações de dependência?", in , O modelo politico brasileiro. São Paulo, Difel/Difusão Editorial S.A.

CARDOSO, Fernando H. \& FALETTO, E. ([1969] 2004), Dependência e desenvolvimento na América Latina. Rio de Janeiro, Civilização Brasileira.

CARDOSO, F. H. \& Serra, José. (1978), “As desventuras da dialética da dependência". Estudos Cebrap, 23: 34-80.

COSTA, Sérgio. (2006), "Desprovincializando a sociologia: a contribuição pós-colonial". Revista Brasileira de Ciências Sociais, 21 (60): 117-134.

CHAKRABARTY, Dipesh. (2000), Provincializing Europe. Princeton, Princeton University Press.

DUSSEL, Enrique. (2000). "Europa, modernidad y eurocentrismo", in Edgardo Lander (ed.), La colonialidad del saber: eurocentrismo y ciencias sociales, Buenos Aires, Clacso.

ESCOBAR, Carlos Henrique. (1975), As ciências e a filosofia. Rio de Janeiro, Imago.
FRANCO, Maria Sylvia de C. (1976), "As ideias estão em seu lugar”. Cadernos de Debate, 1. (1983), Homens livres na ordem escravocrata. 3 ed. São Paulo, Kairos.

GIANNOTTI, José Arthur (1976). "Notas sobre a categoria 'modo-de-produção' para uso e abuso dos sociólogos". Estudos Cebrap, 17: 162-168. (1977), Exercícios de filosofia. São Paulo, Brasiliense.

IANNI, Octavio. ([1965] 2004), Estado e capitalismo. São Paulo, Brasiliense.

JAY, Martin. (1984), Marxism and totality: the adventures of a concept from Lukács to Habermas. Cambridge, Polity Press.

LAHUERTA, Milton. (2005), "Em busca da formação social brasileira: marxismo e vida acadêmica”. Perspectivas, 28: 157-186.

LANDER, Edgardo. (2000), "Ciências sociales: saberes coloniales y eurocéntricos", in (org.), La colonialidad del saber: eurocentrismo y ciencias sociales - perspectivas latinoamericanas, Buenos Aires, Clacso.

LOSURDO, Domenico. (2011), Liberalism: a counter-history. Londres, Verso.

LOVE, Joseph L. (1998), A construção do terceiro mundo. São Paulo, Paz e Terra.

LUKÁCS, Georg. ([1922] 2003), História e consciência de classe. São Paulo, Martins Fontes.

MAIA, João E. (2009), "Pensamento brasileiro e teoria social: notas para uma agenda de pesquisa”. Revista Brasileira de Ciências Sociais, 24: 155-168.

(2011A), "Um capítulo do pensamento social periférico: Guerreiro Ramos e Hussein Alatas". Anais do XV Congresso Brasileiro de Sociologia, Curitiba.

(2011B). "SPACE, social theory and peripheral imagination: Brazilian intellectual history and de-colonial debates". International Sociology, 26: 392-407.

(2012). "Reputações à brasileira: o caso de Guerreiro Ramos". Sociologia \& Antropologia, 2: 265-291.

MARINI, Roy Mauro. (1973), Dialéctica de la dependencia. México, Era.

MARTINS, José de Souza. (2004), O cativeiro da terra. 8. ed. São Paulo, Hucitec. 
MIGNOLO, Walter D. (2000), "La colonialidad a lo largo y a lo ancho: el hemisferio occidental en el horizente colonial de la modernidad", in E. Lander (org.), La colonialidad del saber: eurocentrismo y ciencias sociales perspectivas latinoamericanas, Buenos Aires, Clacso.

(2003), Histórias locais/projetos globais: colonialidade, saberes subalternos e pensamento liminar. Belo Horizonte, Editora da UFMG. (2005), "Human understanding and (Latin) American interests: the politics and sensibilities of geohistorical locations", in $\mathrm{H}$. Schwarz e S. Ray (eds.), A companion to postcolonial studies, Londres, Blackwell.

(2007), "Delinking: the rhetoric of modernity, the logic of coloniality and the grammar of de-coloniality". Cultural Studies, 21: 449-514.

MITCHELL, Timothy. (2000), "The stage of modernity", in (ed.), Questions of modernity, Minneapolis/Londres, University of Minnesota Press.

MOTA, Carlos Guilherme. (2008), Ideologia da cultura brasileira. São Paulo, Editora 34.

MOTTA, Luiz Eduardo. (2000), "O Iseb no banco dos réus". Comum, 5: 119-145.

. (2010), "A política do Guerreiro: nacionalismo, revolução e socialismo no debate brasileiro nos anos 1960". Organização \& Sociedade, 17: 85-101.

NOVAIS, Fernando A. (1986), "Caio Prado Jr. na historiografia brasileira", in R. Moraes, R. Antunes e V. B. Ferrante (orgs.), Inteligência brasileira, São Paulo, Brasiliense.

([1979] 2005a). Portugal e Brasil na crise do antigo sistema colonial (1877-1808).8. ed. São Paulo, Hucitec.

(2005b). "A evolução da sociedade brasileira: alguns aspectos do processo histórico da formação social no Brasil", in Aproximaçōes: estudos de história e historiografia, São Paulo, Cosac Naify.

ORTIZ, Renato. (1985), Cultura brasileira e identidade nacional. São Paulo, Brasiliense.

PALMA, Gabriel. (1981), "Dependency and development: a critical overview", in D. Seers (ed.),
Dependency theory: a critical reassessment, Londres, Pinter.

PIRES, Eginardo. (1978). "Ideologia e Estado em Althusser: uma resposta". Encontros com a Civilização Brasileira, 6: 11-40.

POULANTZAS, Nicos. (1978), Classes sociais no capitalismo de hoje. Rio de Janeiro, Zahar.

PRADO JR., Caio. ([1942] 2008), Formação do Brasil contemporâneo. São Paulo, Brasiliense.

QUARTIM DE MORAES, João. (1984), "Trabalho e reflexão de J. A. Giannotti”. Filosofia e Politica, 1: 143-154.

QUIJANO, Aníbal. (2000), "Colonialidad del poder, eurocentrismo y América Latina", in $\mathrm{E}$. Lander (org.), La colonialidad del saber: eurocentrismo y ciencias sociales - perspectivas latinoamericanas, Buenos Aires, Flacso.

RAMOS, Guerreiro. (1965), A redução sociológica. Rio de Janeiro, Tempo Brasileiro.

RICUPERO, Bernardo. (2008), "Da formação à forma: ainda as ideias fora de lugar". Lua Nova, 73: 59-69.

SAES, Décio. (2007), "O impacto da teoria althusseriana da história na vida intelectual brasileira”, in João Quartim Moraes (org.), História do marxismo no Brasil, 2. ed. Campinas, Editora da Unicamp, vol. 3.

SANTOS, Boaventura de Sousa. (2007), "Para além do pensamento abissal: das linhas globais a uma ecologia de saberes". Novos Estudos, 79: 71-94. . (2006), A gramática do tempo: por uma nova cultura política. São Paulo, Cortez.

SANTOS, Theotônio dos. (1970), Dependencia y cambio social. Santiago, Centro de Estudios Socioeconomicos de la Universided de Chile. (1998), "The theoretical foundations of the Cardoso government: a new stage of the dependency- theory debate". Latin American Perspectives, 25 (1): 53-70.

SAPIRO, Gisèle; Steinmetz, G. \& Ducournau, C. (2010), "La production des représentations coloniales et postcoloniales". Actes de la Recherche en Sciences Sociales, 185: 4-11.

SCHWARZ, Roberto ([1969] 2008). "Cultura e política, 1964-1969”, in —O pai de familia e outros estudos, São Paulo, Companhia das Letras. 
([1987] 2006). "Pressupostos, salvo engano, de 'Dialética da malandragem', in , Que horas são? São Paulo, Companhia das Letras.

. ([1977] 2000a). "Ideias fora do lugar", in $\longrightarrow$ Ao vencedor as batatas: forma literária e processo social nos inícios do romance brasileiro, São Paulo, Editora 34/Duas Cidades. . ([1990] 2000b), Um mestre na periferia do capitalismo. São Paulo, Editora 34/Duas Cidades.

(1998). "Um seminário de Marx”. Novos Estudos Cebrap, 50: 99-114.

SOUZA, Jessé. (2000), A modernização seletiva: uma reinterpretação do dilema brasileiro. Brasília, Editora da UnB.

. (2003), A construção social da subcidadania: para uma sociologia política da modernidade periférica. Rio de janeiro, Iuperj.

TAVOLARO, Sergio B. F. (2005), "Existe uma modernidade brasileira? Reflexões em torno de um dilema sociológico brasileiro". Revista Brasileira de Ciências Sociais, 20 (59): 5-22.

VIOTTI DA COSTA, Emília. (1978), "A revolução burguesa no Brasil”. Encontros com a Civilização Brasileira, 4: 176-186. 


\section{MODERNIDADE PERIFÉRICA E DESCOLONIZAÇÃO EPISTÊMICA: A CONTRIBUIÇẪO DO MARXISMO PAULISTA}

\section{José Henrique Bortoluci}

Palavras-chave: Estudos pós-coloniais; Marxismo paulista; Descolonização epistêmica; Modernidade periférica; Colonialidade.

Nas últimas duas décadas, os estudos pós-coloniais tem avançado severas críticas a modelos de explicação sobre o desenvolvimento histórico em sociedades periféricas e pós-coloniais que se baseiam em um modelo de referências eurocêntricas. Em diálogo com essa literatura, este trabalho busca mostrar como o marxismo paulista das décadas de 1960 e 1970 buscou reconstruir aquelas estruturas categoriais e avançar modelos analíticos críticos a partir de um "ponto de vista periférico", uma vez que a crítica à modernidade brasileira é elaborada como momento de uma crítica à modernidade global. Este artigo mostra como aquele trabalho pioneiro de descolonização epistêmica pelas vias de uma leitura bastante local de Marx fornece pistas para uma ciência social e uma crítica cultural pós-coloniais.

\section{PERIPHERAL MODERNITY AND EPISTEMIC DECOLONIZATION: THE CONTRIBUTION OF THE "MARXISMO PAULISTA"}

\section{José Henrique Bertoluci}

Keywords: Postcolonial studies; Marxismo paulista; Episteme decolonization; Peripheral modernity; Coloniality.

The interdisciplinary field known as Postcolonial Studies has advanced a severe critique of traditional Eurocentric explanatory models of peripheral and postcolonial societies' historical development. In a dialogue with this literature, this paper shows how a Marxist scholarship developed in São Paulo during the 1960s and 1970s ("Marxismo Paulista") attempted to deconstruct Eurocentric categories and to propose critical analytical models from a "peripheral standpoint" - since the critique of Brazilian modernity was elaborated as a moment of a critique of global modernity. This paper also highlights how that groundbreaking work of epistemic decolonization - by means of a very local reading of Marx - provides elements for a renewed postcolonial social science and cultural critique.

\section{MODERNITÉ PÉRIPHÉRIQUE ET DÉCOLONISATION ÉPISTÉMIQUE: LA CONTRIBUTION DU "MARXISME PAULISTE”}

\author{
José Henrique Bortoluci
}

Mots-clés: Études postcoloniales; Marxisme pauliste; Décolonisation épistémique; Modernité périphérique; Colonialisme.

Au cours des deux dernières décennies, les études postcoloniales ont développé plusieurs critiques à l'égard des modèles d'explication sur le développement historique des sociétés périphériques et postcoloniales qui reposent sur un modèle théorique eurocentrique. En dialogue avec cette littérature, cet article prétend indiquer comment le "Marxisme Pauliste" des années 1960 et 1970 a cherché à reconstruire ces structures catégorielles et à faire progresser les modèles analytiques critiques à partir d'un "point de vue périphérique", puisque la critique à la modernité brésilienne s'est élaborée comme un moment de la critique de la modernité mondiale. Cet article met en évidence comment ce travail pionnier de décolonisation épistémique, élaboré au moyen d'une lecture assez locale de Marx, peut fournir des indices pour une science sociale et une critique culturelle postcoloniales. 